\title{
Erythrocyte Agglutination Measurement
}

National Cancer Institute

\section{Source}

National Cancer Institute. Erythrocyte Agglutination Measurement. NCI Thesaurus. Code C111197.

The determination of the amount of erythrocyte agg lutination present in a sample. 